\title{
Kemampuan Salat Anak Usia Dini Melalui Metode Demonstrasi
}

\author{
Habsyi Siti Nurdini ${ }^{1}$, Hilman Mangkuwibawa ${ }^{2}$, Syam'iyah $^{3}$ \\ 1,2,3Pendidikan Islam Anak Usia Dini, Fakultas Terbiyah dan Keguruan, Universitas \\ Islam Sunan Gunung Djati Bandung \\ Panyileunkan Jl. Cimencrang, Cimenerang, Gedebage Kota Bandung, Jawa Barat \\ 40282 \\ Email: ${ }^{1}$ habsyisitin@gmail.com, ${ }^{2 h i l m a n m a n g k u w i b a w a @ u i n s g d . a c . i d, ~}$ \\ 3adesyamiyah@yahoo.com
}

\begin{abstract}
Abstrak
Penelitian bertujuan untuk mengetahui upaya meningkatkan kemampuan salat anak usia dini melalui metode demonstrasi pada kelompok B RA Al-Furqon. Penelitian ini adalah penelitian tindakan kelas (classroom research) dengan melalui empat tahap yaitu: prencanaan, pelaksanaan, observasi dan refleksi. Metode pembelajaran yang digunakan adalah metode demonstrasi. Teknik pengumpulan data menggunakan observasi dan dokumentasi. Analisis data digunakan dengan deskriptif kualitatif. Hasil penelitian dari penerapan metode demonstrasi pada pembelajaran praktik salat kelompok B RA Al-Furqon dapat disimpulkan bahwa adanya perkembangan hasil pembelajaran praktik salat siswa. Peningkatan ini dapat dilihat dari nilai rata-rata seluruh siswa yaitu dari hasil pra sikuls sebesar 31,3. Pada siklus I rata-rata nilai seluruh siswa yaitu 51,7 dan pada siklus II naik menjadi 77,5 . Pada pra siklus perkembangan salat anak usia dini terdapat delapan orang yang belum berkembang (BB) dan lima orang mulai berkembang (MB). Pada siklus I perkembangan salat anak usia dini mencapai enam orang yang mulai berkembang $(\mathrm{MB})$ dan delapan orang berkembang sesuai harapan (BSH), kemudian pada siklus II perkembangan salat anak usia dinimencapai empat orang yang berkembang sesuai harapan (BSH) dan sembilan orang berkembang sangat baik (BSB).
\end{abstract}

Kata kunci: Anak usia dini, metode demonstrasi, salat.

\section{Abstract}

The study aims to determine the efforts to improve the ability of early childhood prayer through demonstration methods in group B RA Al-Furqon. This study is a classroom action research through four stages: planning, implementation, observation and reflection. The learning method used is the demonstration method. Data collection techniques use observation and documentation. Data analysis was used with qualitative descriptive. The results of the study of the application of the demonstration method on 
learning the practice of RA Al-Furqon group B prayer can be concluded that there is a development of the results of learning the practice of student prayer. This increase can be seen from the average value of all students, namely from pre-cyclic results of 31.3. In the first cycle the average value of all students was 51.7 and in the second cycle it rose to 77.5. In the pre-development cycle of early childhood prayer there are eight undeveloped people $(\mathrm{BB})$ and five people begin to develop $(\mathrm{MB})$. In the first cycle the development of early childhood prayer reached six people who began to develop (MB) and eight people developed according to expectations (BSH), then in the second cycle the development of early childhood prayer reached four people who developed according to expectations (BSH) and nine people developed very well (BSB).

Keywords: Early childhood, method of demonstration, prayer.

\section{Pendahuluan}

Pendidikan anak usia dini merupakan jenjang pendidikan formal sebagaimana menurut Undang-Undang Republik Indonesia No. 20 Tahun 2003 tentang Sistem Pendidikan Nasional, yang berbunyi:

Pendidikan anak usia dini (PAUD) adalah suatu upaya pembinaan yang dilakukan anak sejak lahir sampai usia enam tahun, yang dilakukan melalui pemberian rangsangan pendidikan untuk membantu pertumbuhan dan perkembangan jasmani dan rohani, agar anak memiliki kesiapan dalam memasuki pendidikan lebih lanjut.

Pada situasi saat ini semua aspek perkembangan yang ada pada diri anak usia dini tumbuh dan berkembang secara cepat dan hebat. Pada tahap ini dibutuhkan suatu rangsangan dari orang-orang terdekat. Sehingga pertumbuhan dan perkembangannya tidak terhambat. Perkembangan diharapkan terjadi dengan proses yang progresif, terus maju kedepan, tidak mundur, dan berkesinambungan.

Aspek yang harus dikembangkan pada masa ini meliputi aspek perkembangan nilai agama dan moral, aspek perkembangan fisik motorik, aspek perkembangan kognitif, aspek perkembangan bahasa, aspek perkembangan sosial emosional, dan aspek perkembangan seni. Semua aspek perkembangan tersebut perlu dikembangkan sejak usia dini agar pertumbuhan dan berkembangnya tercapai secara optimal, salah satunya dalam aspek perkembangan nilai agama dan moral. Perkembangan ini harus dimiliki oleh anak untuk menjadi manusia yang baik dan taat kepada Allah, anggota keluarga, dan anggota masyarakat. 
Salah satu tingkat pencapaian perkembangan anak pada perkembangan nilai agama dan moral adalah memperkenalkan beribadah sederhana yaitu beribadah salat. Salat merupakan ibadah yang paling pokok bagi setiap muslim karena salat merupakan tiang agama. Tujuan salat adalah untuk mengingat kepada Allah subhanahu wa taala sebagai tahap mempertebal iman dan ketakwaan seorang hamba.

Menurut Hakim (2000:210), ibadah salat merupakan salah satu bentuk realisasi dari ketakwaan seorang muslim. Salat di lakukan untuk mengingat (Dzikir) kepada Allah agar senantiasa jiwa tenang dan damai. Dengan memperkenalan salat sejak usia dini diharapkan mampu membentuk perilaku keagaman dan menanamkan konsep keagamaan dalam mengenal siapa Tuhannya.

Salat sangat penting untuk dikenalkan kepada anak usia dini agar keterampilan salat yang sudah diajarkan ketika mereka kecil mampu dipertahankan sampai mereka tumbuh menjadi manusia dewasa. Diharapkan mereka mampu melaksanakan salat dengan baik dan benar yang sesuai dengan tuntunan syariat yang telah di tentukan.

Dalam mengajarkan ibadah salat kepada anak usia dini dibutuhkan suatu metode yang tepat. Metode menurut (Hidayat dan Aisyah, 2015:23) adalah cara kerja yang teratur dan sistematis untuk melaksanakan suatu kegiatan sehingga dapat mencapai suatu tujuan. Bagi anak usia dini pembelajaran yang paling mudah dipahami serta mudah untuk diingat diantaranya dengan menggunakan metode demonstrasi. Metode demonstrasi menurut Sudjana (2011:83) merupakan suatu metode mengajar yang sangat efektif, sebab membantu siswa untuk mencari jawaban dengan usaha sendiri berdasarkan data yang benar. Karena metode demonstrasi merupakan pembelajaran yang cara menyampaikan materi secara langsung memperlihatkan bagaimana proses terjadinya sesuatu.

Hasil studi pendahuluan yang dilakukan pada kelompok B terdapat permasalahan berkenaan dengan rendahnya pembelajaran praktik salat. Dapat dilihat dari gerakan yang dilakukan ketika praktik salat berlangsung sekaligus bacaannya yang masih belum fasih dari mulai takbir sampai dengan salam. Berdasarkan hal tersebut, penulis melakukan penelitian dengan tujuan yang hendak akan dicapai dalam penelitian ini adalah untuk mengetahui: (1) realitas kemampuan salat anak usia dini sebelum penerapan metode demonstrasi; (2) realitas proses penerapan metode demonstrasi dalam meningkatkan kemampuan salat anak usia dini pada setiap siklus; dan (3) realitas kemampuan salat anak usia dini setelah penerapan metode demonstrasi. 


\section{Metodologi}

Teknik yang digunakan dalam penelitian ini yaitu menggunakan instrumen penilaian observasi dan dokumentasi. Sugiyono (2014:203) mengungkapkan bahwa observasi digunakan bila peneliti berkenaan dengan prilaku manusia, proses kerja, gejala-gejala alam dan bila responden yang diamati tidak terlalu besar. Sedangkan Yus (2011:120) berpendapat bahwa observasi merupakan penilaian yang dilakukan dengan mengamati prilaku dan aktivitas anak dalam suatu waktu atau kegiatan. Observasi dalam hal ini untuk mengamati segala aktivitas yang sedang dilakukan guru terhadap murid mengenai proses pembelajaran salat yang dilakukan melalui metode demonstrasi pada anak kelas B di RA AI-Furqon Ciranjang Cianjur tahun pelajaran 2017-2018. Selanjutnya, instrumen yang digunakan dalam penelitian adalah dokumentasi. Menurut Sugiyono (2015:329), dokumentasi merupakan catatan peristiwa yang sudah berlalu. Dokumentasi bisa berbentuk tulisan, gambar atau karya-kaya monumental dari seseorang. Dokumentasi digunakan sebagai alat untuk mengambil gambar berupa kegiatan yang dilakukan selama proses pembelajaran salat berlangsung.

Sumber data dalam penelitian ini dibagi ke dalam data primer dan sekunder. Data primer merupakan data yang bersumber dari subjek penelitian yang dapat memberikan informasi terhadap penelitian yang akan dilakukan. Sumber data primer adalah siswa kelompok B RA Al-Furqon. Semester I pada tahun ajaran 2018-2019. Dengan jumlah anak 13 orang, yang terdiri dari tiga anak laki-laki dan 10 anak perempuan. Sedangkan data sekunder adalah data yang diperoleh dari guru wali kelas berkenaan dengan praktik salat kelompok B RA AL-Furqon.

Tipe data penelitian ini termasuk kedalam dua jenis data yaitu data kuantitaif dan data kualitatif. Data kuantitaif pada penelitian ini meliputi hasil belajar siswa terhadap kemampuan salat anak dengan menggunakan metode demonstrasi yang diperoleh dari hasil pengamatan yang dilakukan disetiap siklus. Adapun data kualitatif pada penelitian ini diperoleh dari lembar observasi siswa dan guru selama pembelajaran berlangsung dan dokumentasi selama proses kegiatan mengajar.

Analisis data dalam penelitian tindakan kelas adalah data kualitatif dan data kuantitatif. Data kualitatif yaitu data yang berupa hasil observasi selama pembelajaran salat berlangsung sedangkan data kuantitaif merupakan data hasil praktik salat siswa setelah mereka melakukan proses pembelajaran dengan menggunakan metode 
demonstrasi. Maka setelah itu data hasil praktik pembelajaran salat dihitung dengan cara-cara dibawah ini:

1. Data hasil observasi untuk mengukur aktivitas guru dan siswa, dengan rumus sebagai berikut:

Persentase $=\frac{\text { jumlah aktivitas yang tercapai }}{\text { seluruh aktivitas }} \times 100 \%$

2. Data hasil praktik salat.

Menghitung persentase perkembangan setiap nomor item yang dicapai oleh setiap siswa, dengan menggunakan rumus:

$$
\frac{\text { Skor yang dicapai siswa }}{\text { skor maksimal }}=\times 100
$$

(Hayati,2013:152)

\section{Hasil dan Diskusi}

Berdasarkan hasil praktik pembelajaran salat siklus II, perkembangan pembelajaran praktik salat siswa telah mencapai pada tarap berhasil. Hal ini dapat dilihat dari hasil praktik salat anak usia dini sebelum menggunakan metode demonstrasi terdapat delapan orang yang belum berkembang (BB) dan lima orang mulai berkembang (MB). Pada siklus I perkembangan salat anak usia dini mencapai enam orang yang mulai berkembang $(\mathrm{MB})$ dan tujuh orang berkembang sesuai harapan $(\mathrm{BSH})$, kemudian pada siklus II perkembangan salat anak usia dini mencapai empat orang yang berkembang sesuai harapan $(\mathrm{BSH})$ dan sembilan orang berkembang sangat baik (BSB). Data perkembangan praktik salat anak usia dini dapat dilihat pada tabel dibawah ini:

Tabel 1. Data hasil perkembangan salat siswa

\begin{tabular}{cccc}
\hline Kriteria Penilaian & $\begin{array}{c}\text { Jumlah siswa } \\
\text { pada pra siklus }\end{array}$ & $\begin{array}{c}\text { Jumlah siswa } \\
\text { pada siklus I }\end{array}$ & $\begin{array}{c}\text { Jumlah siswa pada } \\
\text { siklus II }\end{array}$ \\
\hline BSB & - & - & 9 \\
BSH & - & 7 & 4 \\
MB & 5 & 6 & - \\
BB & 8 & - & - \\
\hline
\end{tabular}

Sumber: Hasil Penelitian, 2018

Rata-rata nilai keseluruhan siswa meningkat secara signifikan dari nilai pra siklus yaitu 31,3 menjadi 51,7 pada siklus I dan 77,5 pada siklus II. Maka untuk mengetahui peningkatan rata-rata nilai seluruh siswa maka dapat dilihat pada diagram batang dibawah ini: 
Grafik 1. Peningkatan nilai rata-rata

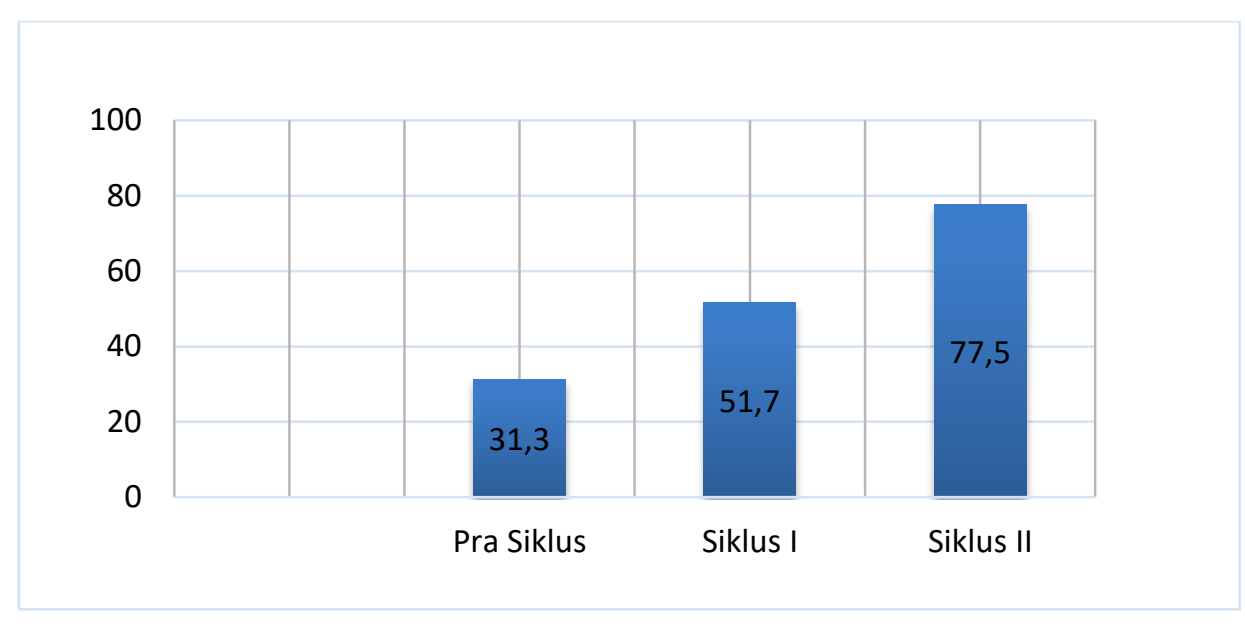

Sebagaimana keterangan pada Tabel 1 dan Grafik 1 metode demostrasi dapat meningkatkan kemampuan salat anak usia dini. Hal ini dikaitkan dengan pendapat Gordon dan Jeannette (dalam Yus, 2011:168) bila anak belajar dengan cara melakukan akan memberi peluang sebesar $90 \%$ berhasil. Salah satu metode belajar yang memberi peluang berhasil yaitu metode demonstrasi. Metode demonstrasi menurut pendapat Isjoni (2010:92) berarti menunjukan, mengerjakan, dan menjelaskan cara-cara mengerjakan sesuatu. Melalui demonstrasi diharapkan anak dapat mengenal langkahlangkah pelaksanaan. Pembelajaran ini digunakan sebagai metode mengajar dengan melakukan praktik langsung yang dilakukan dengan berjamaah. Sebagaimana menurut hasil penelitian dari Vernon Magnese (dalam Fatmawati, 2015:3) bahwa seseorang dalam belajar mendapat pemahaman atau daya ingat dari hasil proses belajar dalam membaca $20 \%$, mendengarkan $30 \%$, melihat $40 \%$, mengucapkan $50 \%$, melakukan $60 \%$, sedangkan melihat, mengucapkan, mendengarkan dan melakukan $90 \%$.

Proses pembelajaran praktik salat yang dilakukan melalui metode demonstrasi dengan cara memperlihatkan, mengucapkan, mendengarkan, dan melakukan kepada anak maka, anak akan mudah memahami materi yang disampaikan oleh guru. Metode ini dalam prakteknya menirukan gerakan serta menirukan bacaan secara berulang-ulang yang menyebabkan mudahnya informasi untuk masuk kedalam memori jangka panjang, sehingga peserta didik merekam semua kejadian yang dilihatnya. Sebagaimana menurut Sternberg (Jayani dan Hastjarjo, 2011:432) bahwa memori jangka panjang merupakan sistem penyimpanan informasi jangka panjang dengan kapasitas yang sangat besar dan dapat diungkapkan sewaktu-waktu. 


\section{Penutup}

Berdasarkan hasil penelitian dan pembahasan dapat disimpulkan bahwa pembelajaran praktik salat melalui metode demonstrasi dapat meningkatkan kemampuan praktik salat anak usia dini, hal tersebut dapat dilihat dari pembelajaran praktik salat sebelum menggunakan metode demonstrasi sangat rendah sekali. Pada pra siklus perkembangan pembelajaran praktik salat anak usia dini terdapat delapan orang yang belum berkembang (BB) dan lima orang mulai berkembang (MB). Sedangkan ketika proses pembelajaran praktik salat pada siklus I perkembangan salat anak usia dini sudah mulai berkembang diantaranya dari 13 orang siswa terdapat enam orang yang mulai berkembang (MB) dan delapan orang berkembang sesuai harapan $(\mathrm{BSH})$, kemudian perkembangan pembelajaran praktik salat anak usia dini meningkat secara signifikan dari tiga belas orang siswa mencapai empat orang yang berkembang sesuai harapan $(\mathrm{BSH})$ dan sembilan orang berkembang sangat baik (BSB). Penelitian ini hanya mengambil masalah dengan ruang lingkup atau wilayah penelitian yang terbatas. Oleh karena itu dipersilahkan peneliti lain untuk melakukan penelitian ulang dengan wilayah yang lebih luas dan masalah yang lebih mendalam.

\section{Daftar Pustaka}

Departement. Pendidikan Nasional. (2003). Undang-undang republik Indonesia no 20 tahun 2003 tentang sistem pendidikan nasional. Jakarta. Depdiknas.

Fatmawati. 2015. Pengaruh penerapan pembelajaran model SAVI yang menggunakan metode brainstroming terhadap konsitensi konsepsi dan peningkatan kemampuan kognitif siswa sma pada materi fluida statis. Skripsi. Universitas Pendidikan Indonesia. （ $\quad$ http://repository.upi.edu/18080/6/T FIS 1303017 Chapter1.pdf. Diakses pada tanggal 22022018. Jam 13:54).

Hakim, AA. 2000. Metodologi Studi Islam. Bandung: PT. Remaja Rosdakarya.

Hayati, T. 2013. Evaluasi pembelajaran. Bandung CV. Insam Mandiri.

Hastjarjo, dan Jayani. 2011. Pengaruh frekuensi pemberian tes terhadap memori jangka panjang bacaan pada siswa SMA. Jurnal Psikologi. Volume 6. No 2. Universitas Gadjah Mada. (https://media.neliti.com/media/publications/126748-IDpengaruh-frekuensi-pemberian-tes-terhada.pdf. Diakses pada tanggal 23042018 jam 20:52) 
Hidayat, dan Aisyah. 2015. Aktvitas mengajar anak TK/RA dan PAUD. Bandung. Arfino Raya.

Isjoni. 2010. Model pembelajaran Anak usia dini. Bandung: Alfabeta.

Sugiyono. 2014. Metode Penelitian Pendidikan Pendekatan Kuantitatif, Kualitatif danR\&D. Bandung: Alfabeta.

Sugiyono. 2015. Metode Penelitian Pendidikan (Pendekatan Kuantitatif, Kualitatif dan $R \& D)$. Bandung CV :Alfabeta.

Sudjana, N. 2011. Dasar-dasar Proses Belajar Mengajar. Bandung: Sinar Baru Algensindo Offset.

Yus, A. 2011. Penilaian perkembangan belajar anak taman kanak-kanak. Jakarta: Kencana.

\section{Biodata Penulis}

Habsyi Siti Nurdini, Lahir di Cianjur 27 Juli 1996, telah menyelesaikan pendidikan S1 pada Program Studi Pendidikan Islam Anak Usia Dini di Fakultas Tarbiyah dan Keguruan UIN Sunan Gunung Djati Bandung (2018).

Hilman Mangkuwibawa, lahir di Bandung 03 Juni 1965, telah menyelesaikan pendidikan S1 jurusan Pendidikan Khusus di Fakultas IImu Pendidikan IKIP Bandung (1993). S2 Jurusan Pendidikan Kebutuhan Khusus/BP-BAK di Fakultas IImu pendiidikan UPI Bandung (2010). Merupakan dosen di Program Pendidikan Islam Anak Usia Dini Fakultas Tarbiyah dan Keguruan UIN Sunan Gunung Djati Bandung bidang yang ditekuni antara lain Psikologi Pendidikan, Bimbingan dan Konseling, Metodologi Penelitian dan Pendidikan Anak Berkebutuhan Khusus.

Syam'iyah, lahir di Bekasi 11 Juli 1977, telah menyelesaikan pendidikan S1 di Fakultas tarbiyah dan keguruan IAIN Sunan Gunung Djati Bandung (2001), S2 Program Pendidikan Bahasa Arab UIN Sunan Gunung Djati Bandung (2007). Dan sedang melanjutnkan S3 di UIN Sunan Gunung Djati Bandung. 